\title{
Desempenho, comportamento ingestivo e características de carcaça de cordeiros confinados submetidos a diferentes frequências de alimentação
}

\author{
Edson Luis de Azambuja Ribeiro ${ }^{1}$, Ivone Yurika Mizubuti ${ }^{1}$, Leandro das Dores Ferreira da \\ Silva $^{1}$, Fernando Henrique Pereira de Paiva², Cícero Leandro de Sousa ${ }^{2}$, Filipe Alexandre \\ Boscaro de Castro ${ }^{3}$
}

\footnotetext{
1 Departamento de Zootecnia, UEL, Caixa Postal 6001 - 86051-990 - Londrina, PR.

2 Curso de Zootecnia - UEL.

3 Programa de Pós-graduação em Ciência Animal - UEL.
}

RESUMO - Objetivou-se com este trabalho avaliar o efeito da frequência de alimentação sobre o desempenho, o comportamento ingestivo e as características de carcaça de cordeiros em confinamento. Foram utilizados 18 cordeiros mestiços Santa Inês, não-castrados, com peso corporal inicial de 22,79 \pm 4,28 kg. Os animais foram confinados durante 56 dias em baias coletivas em aprisco coberto, com piso ripado, distribuídos ao acaso de acordo com a frequência de alimentação: uma, duas e três vezes/dia. A dieta (16,7\% de PB e 70,3\% de NDT) foi a mesma para todos os grupos. O ganho de peso diário, o consumo de ração, a conversão alimentar, o comportamento ingestivo e as características de carcaça não foram afetados pela frequência de alimentação. Com exceção da largura da perna, as demais medidas biométricas realizadas nas carcaças não foram influenciadas pela frequência de alimentação. Entre os componentes do peso vivo não pertencentes à carcaça, apenas o rendimento dos intestinos cheios e o conteúdo do trato digestório foram afetados, pois foram menores nos animais com uma alimentação diária. O aumento na frequência de alimentação quando fornecidas dietas com 16,7\% de PB e 70,3\% de NDT não influencia o desempenho, o comportamento ingestivo e as características de carcaça de cordeiros em confinamento, assim, pode-se utilizar apenas uma alimentação ao dia.

Palavras-chave: arraçoamento, confinamento, etologia, ganho de peso diário, ovinos

\section{Performance, ingestive behavior and carcass characteristics of feedlot lambs submitted to different feeding frequencies}

\begin{abstract}
This work evaluated the effect of feeding frequencies on performance, ingestive behavior and carcass characteristics of fedlot lambs. Eighteen non-castrated Santa Inês crossbreed lambs, with initial live weight of $22.79 \pm 4.28 \mathrm{~kg}$ were used in the experiment. The animals were confined for 56 days in collective pens in a slotted floor sheep barn. The animals were randomly distributed, according to the feeding frequency: once, twice and three times/day. The diet (16.7\% of CP and 70.3\% TDN) was the same for all groups. The average daily gain, ration consumption, feed conversion, ingestive behavior and carcass characteristics were not affected by feeding frequency. Except for leg width, the other body measurements performed on the carcass were not influenced by feeding frequency. Among non-carcass live weight components, only yield of full intestine and digestive tract content were affected, because they were smaller for animals that received one feeding daily. The increase on feeding frequencies when diets containing $16.7 \%$ CP and $70.3 \%$ TDN were offered does not affect performance, the ingestive behavior and characteristics of carcass of confined lambs. Therefore, only one feeding per day can be used.
\end{abstract}

Key Words: average daily gain, confinement, etology, feeding, sheep

\section{Introdução}

O manejo alimentar adequado é fundamental para o sucesso da produção animal, onde se busca ajustar o aporte nutricional com as exigências dos animais. Na produção de carne ovina, além de bons índices produtivos, as carcaças e carnes produzidas devem ter qualidade, a fim de satisfazer o mercado consumidor (Jardim et al., 2000). A terminação de cordeiros em confinamento pode ser utilizada com esta finalidade, pois apresenta uma série de benefícios, como menor mortalidade dos animais, em razão do maior controle sanitário, além de melhor controle das dietas. Entretanto, os custos do confinamento geralmente são elevados. Segundo Beserra et al. (2007), uma alternativa para redução desses custos seria a diminuição na frequência de alimentação e consequentemente da utilização de mão-de-obra. 
O conhecimento do comportamento ingestivo é uma ferramenta de grande importância na avaliação de dietas, pois possibilita ajustar o manejo alimentar dos animais para obtenção de melhor desempenho produtivo e reprodutivo (Cavalcanti et al., 2008). De acordo com Ferreira (2006), os fatores que influenciam o consumo de alimentos em ruminantes podem estar ligados ao animal (raça, sexo e peso corporal), alimento (composição da dieta, forma física e palatabilidade), manejo e ambiente. Entre estes últimos fatores, o tempo de acesso ao alimento, a frequência de alimentação, o espaço disponível, o fotoperíodo, a temperatura e umidade são os mais relevantes.

De acordo com Osório (1992) e Carvalho et al. (2007b), na produção de carne ovina também devem ser considerados os componentes do peso corporal não pertencentes a carcaça ou componentes não carcaça, geralmente não considerados na comercialização dos animais. Esses componentes, todavia, devem ser valorizados economicamente, já que podem ser utilizados como alimento (coração, fígado e rins) ou para outros fins, como na indústria de vestuários (pele), podendo perfazer até $60 \%$ do peso corporal do animal (Carvalho et al., 2007b).

Este trabalho foi realizado com o objetivo de avaliar o efeito da frequência de alimentação sobre o desempenho, o comportamento ingestivo e as características de carcaça de cordeiros em confinamento.

\section{Material e Métodos}

O experimento foi realizado no setor de ovinos da Fazenda Escola (FAZESC) da UEL no período de março a maio de 2008. Dezoito cordeiros mestiços Santa Inês, com peso corporal inicial de $22,79 \pm 4,28 \mathrm{~kg}$, foram alojados em baias coletivas em aprisco coberto com piso ripado e divididos em três grupos de acordo com a frequência de alimentação, uma ( 8 h), duas ( 8 e 18 h) e três vezes ao dia ( 8,13 e $18 \mathrm{~h})$, em regime de confinamento durante 56 dias, precedidos de sete dias para adaptação às instalações e dieta.

Os animais foram distribuídos em delineamento inteiramente casualizado, com três frequências de alimentação e seis repetições. Todos os grupos receberam a mesma dieta (Tabelas 1 e 2), elaborada para ganhos de 250 g/dia (NRC, 1985; 2007). As análises de matéria seca (MS), proteína bruta (PB), extrato etéreo (EE) e fibra em detergente neutro (FDN) foram realizadas segundo procedimentos descritos por Silva \& Queiroz (2002). A quantidade de alimento ofertada foi ajustada de acordo com o consumo no dia anterior, de maneira a permitir sobras de $10 \%$ do total oferecido. Os animais tiveram acesso irrestrito à água.

Os animais foram pesados no início do experimento e semanalmente até o abate, sendo cada pesagem precedida por jejum de sólidos de 18 horas. Para obtenção do ganho de peso diário, usou-se a equação: (Peso corporal final Peso corporal inicial)/56.

Para estimativa do consumo de matéria seca, foram feitos registros diários, por baia, da oferta e das sobras da dieta. As quantidades totais do ofertado e das sobras foram divididas pelo número de dias (56) em confinamento, desta forma obteve-se a quantidade média diária da oferta e das sobras. Diariamente, amostras do ofertado e das sobras foram recolhidas para determinação da matéria seca em laboratório. De posse dos teores de matéria seca, determinaram-se as quantidades médias de matéria seca ofertada e das sobras e, por diferença dos dois valores, obteve-se o consumo médio diário de matéria seca por baia. Para obtenção do consumo médio diário (CMS) por animal, dividiu-se o consumo da baia pelo número de animais na

Tabela 2 - Composição da dieta experimental

\begin{tabular}{lc}
\hline Ingrediente & $\%$ na matéria seca \\
\hline Silagem de sorgo & 47,0 \\
Milho grão triturado & 29,1 \\
Farelo de soja & 21,2 \\
Óleo vegetal & 1,2 \\
Ureia & 0,5 \\
Sal mineral & 1,0 \\
Composição nutricional & \\
Matéria seca & 61,6 \\
Proteína bruta & 16,7 \\
Extrato etéreo & 3,4 \\
Fibra em detergente neutro & 34,5 \\
Nutrientes digestíveis totais & 70,3
\end{tabular}

Tabela 1 - Composição dos ingredientes da dieta experimental (\% na matéria seca)

\begin{tabular}{lcccc}
\hline Ingrediente & Matéria seca & Proteína bruta & Extrato etéreo & Fibra em detergente neutro \\
\hline Silagem de sorgo & 31,0 & 5,9 & 1,9 & 59,0 \\
Milho grão & 88,0 & 9,0 & 3,8 & 13,6 \\
Farelo de soja & 88,5 & 47,0 & 1,2 & 13,5 \\
Óleo vegetal & 100 & 0,0 & 99,0 & 0,0 \\
Ureia & 100 & 262,0 & 0,0 & 0,0 \\
Sal mineralizado & 100 & 0,0 & 0,0 & 0,0 \\
\hline
\end{tabular}

${ }^{1}$ Nutrientes digestíveis totais, adaptado de Campos (1995) e Valadares Filho et al. (2006). 
baia. O consumo médio diário, em percentagem do peso corporal (PC), foi obtido pela equação: CMS (\%PC) = (CMS*100) / PC médio.

Como os resultados para consumo representavam uma média geral por animal por baia, para possibilitar a análise estatística, foi necessário estimar o consumo médio para cada animal na baia. Para tanto, usou-se o tempo que cada cordeiro gastou ingerindo alimentos. Então, para os cordeiros que apresentaram tempo de ingestão de alimentos igual à média da baia, atribuiu-se valor de consumo de matéria seca igual à média da baia. Seguindo esse raciocínio, para os cordeiros que gastaram mais (ou menos) tempo ingerindo alimentos, somou-se ou diminui-se da média o desvio-padrão, em percentagem, do tempo ingerindo alimentos para cada baia. Para os demais cordeiros na baia, as estimativas de consumo foram feitas por interpolação. Dessa maneira, para os cordeiros que despenderam mais tempo ingerindo alimentos, atribuíram-se maiores valores para consumo de matéria seca e, para os que despenderam menos tempo, os menores valores de consumo. A conversão alimentar foi calculada como consumo de matéria seca em kg dividido pelo ganho de peso diário.

Para registro do comportamento, no $28^{\circ}$ dia do experimento, os cordeiros foram observados a cada dez minutos, durante 24 horas, para determinação dos tempos e das frequências despendidos para ingestão de sólidos, ruminação e ócio (Carvalho et al., 2007a), considerando-se ócio o tempo em que o animal não estava ingerindo alimentos ou ruminando.

Concluído o período de confinamento, os animais foram pesados para obtenção do peso corporal final e transportados para abatedouro particular, com inspeção municipal. Para o abate, os animais foram insensibilizados com choque elétrico, seguido de sangria. Imediatamente após a esfola e evisceração, foram registrados os pesos das carcaças quentes (PCQ) e dos componentes não-carcaça. O rendimento de carcaça quente (RCQ) foi obtido pela equação: $\mathrm{RCQ}=((\mathrm{PCQ} /$ Peso corporal final $) \times 100))$. O trato gastrintestinal foi pesado cheio e vazio para obtenção do peso do corpo vazio (PCV) e rendimento verdadeiro (RV), em que PCV $=$ Peso corporal final - peso do conteúdo gastrintestinal e RV = $((\mathrm{PCQ} / \mathrm{PCV}) \times 100)$.

Conforme metodologia descrita por Osório \& Osório (2005), foram feitas mensurações de comprimento interno de carcaça, profundidade de tórax, comprimento, largura e profundidade da perna, comprimento e perímetro da paleta, além da espessura de gordura de cobertura, determinada sobre o músculo longissimus dorsi entre a $12^{\underline{a}}$ e $13^{\underline{a}}$ costelas.

Os dados obtidos foram submetidos à análise de variância utilizando-se o pacote estatístico SAS (1994). Nas características em que houve significância, as médias foram comparadas pelo teste Tukey, considerando-se o nível de significância de $5 \%$.

\section{Resultados e Discussão}

O desempenho dos cordeiros não foi afetado $(\mathrm{P}>0,05)$ pela frequência de alimentação (Tabela 3). Rakes et al. (1961) observaram que ovinos machos com 2,5 anos de idade, alimentados uma ou oito vezes ao dia, apresentaram ganho em peso diário e eficiência de ganho (ganho em peso/ consumo de ração) similares. Por outro lado, quando os autores avaliaram a frequência de alimentação (uma ou oito vezes ao dia) em animais jovens (seis meses de idade), observaram que aqueles alimentados oito vezes/dia ganharam $65 \%$ a mais em peso. Kozloski et al. (2009) observaram que a fonte da proteína dietética pode ser um importante fator a afetar o consumo, onde observaram em cordeiros alimentados uma ou duas vezes ao dia, que não houve diferença no consumo quando a fonte de proteína era ureia, porém com fonte de proteína verdadeira (caseinato) os cordeiros alimentados duas vezes consumiram mais matéria seca que aqueles alimentados uma vez. Ferreira (2006) não observou diferença no ganho de peso, no consumo de matéria seca e na conversão alimentar em novilhos ou vacas alimentados duas, três ou quatro vezes ao dia em confinamento, da mesma maneira que Pazdiora (2008) em vacas ou novilhas em confinamento alimentadas uma ou duas vezes ao dia.

Tabela 3 - Características de desempenho de cordeiros em confinamento, de acordo com a frequência de alimentação

\begin{tabular}{|c|c|c|c|c|c|c|}
\hline \multirow[t]{2}{*}{ Variável } & \multicolumn{3}{|c|}{ Frequência de alimentação } & \multirow[t]{2}{*}{ Média geral } & \multirow[t]{2}{*}{ CV (\%) } & \multirow[t]{2}{*}{ Probabilidade } \\
\hline & 1 & 2 & 3 & & & \\
\hline Peso inicial (kg) & 22,62 & 22,80 & 22,95 & 22,79 & 19,99 & 0,9920 \\
\hline Ganho em peso diário (kg) & 0,269 & 0,298 & 0,287 & 0,287 & 17,59 & 0,5637 \\
\hline Consumo de matéria seca, (kg/dia) & 1,26 & 1,22 & 1,17 & 1,22 & 21,49 & 0,7949 \\
\hline Consumo de matéria seca (\%PC) & 4,19 & 4,17 & 3,97 & 4,11 & 11,15 & 0,5683 \\
\hline
\end{tabular}

$\mathrm{PC}=$ peso corporal; $\mathrm{PC}^{0,75}=$ peso metabólico. 
A média de ganho em peso diário $(0,287 \mathrm{~kg})$ foi maior que a preconizada $(0,250 \mathrm{~kg})$ pelo NRC (1985) para cordeiros com $20 \mathrm{~kg}$ e com moderado potencial de ganho, recebendo dietas com níveis de proteína e energia, respectivamente, de $81,8 \%$ de NDT e $16,8 \%$ de PB.

Os resultados para consumo de matéria seca (\%PC e $\mathrm{kg} / \mathrm{PC}^{0,75}$ ), ganho de peso diário e conversão alimentar são bastante próximos aos observados por Pereira et al. (2008) em cordeiros Santa Inês recebendo dietas com polpa cítrica úmida prensada, com níveis de proteína e energia similares ao deste estudo.

O desempenho semelhante entre as três frequências de alimentação pode ser explicado pela homogeneidade dos animais no início do experimento, por pertencerem ao mesmo grupamento genético e apresentarem pesos corporais iniciais similares. Variações no desempenho geralmente estão relacionadas a diferenças entre grupos genéticos, dietas, sexo ou condição sexual, entre outros (Arnold \& Meyer, 1988; Ribeiro et al., 2002; Ribeiro et al., 2003).

Diferenças no consumo poderiam surgir, ainda, pela maior ou menor estabilidade aeróbia da silagem, pois, quando é fornecida nos cochos, entra em contato com o ar, deteriorando-se e perdendo nutrientes (Gimenes et al., 2006), podendo ser rejeitada pelos animais. Outro fator que geralmente influencia o consumo em confinamentos é que sempre que o alimento é distribuído nos cochos os animais são estimulados a ingerir (Chase et al., 1976), fato não observado neste estudo.

Os tempos de ingestão, ruminação e ócio não foram afetados pela frequência de alimentação (Tabela 4), resultados que diferem daqueles relatados por Beserra et al. (2007), em pesquisa com caprinos. Esses autores observaram que a ingestão, ruminação, outras atividades e ócio foram afetadas $(\mathrm{P}<0,05)$ pela frequência de alimentação, uma vez que os animais recebendo a dieta de uma única vez demandaram mais tempo no consumo e ruminação que os alimentados duas vezes ao dia. Pazdiora (2008), apesar de não ter observado diferença no consumo de matéria seca em novilhas alimentadas uma ou duas vezes ao dia, notou que aquelas alimentadas duas vezes empregaram mais tempo alimentando-se e tiveram menos tempo de ócio.

Os animais gastaram, em média, 263 e 454 minutos/dia, respectivamente, na ingestão e ruminação dos alimentos (Tabela 4). Esses valores são menores que os reportados por Carvalho et al. (2007a) para cordeiros de mesma raça recebendo uma dieta com relação volumoso:concentrado de 60:40 e alimentados duas vezes ao dia (324 e 631 minutos, respectivamente). Macedo et al. (2007) também encontraram maior tempo de alimentação (405 minutos) e ruminação (490 minutos), porém em cordeiros que receberam dietas com teores maiores de fibra em detergente neutro (FDN).

A similaridade no consumo de matéria seca (Tabela 3) e no tempo ingerindo alimentos e ruminando (Tabela 4) provavelmente está relacionada à composição da dieta, mesma para as três frequências de alimentação. De acordo com Van Soest (1994), o teor de FDN encontra-se inversamente relacionado ao consumo de matéria seca, de maneira que dietas com teores mais elevados de FDN resultam invariavelmente em menores consumos. Kozloski et al. (2006) observaram que o aumento nos níveis de FDN na dieta de cordeiros, de 25 para $43 \%$, afetou negativamente o consumo e a digestibilidade da matéria seca. Os autores citaram que a inclusão em torno de 30\% de FDN representa o nível mais adequado para dietas a base de silagem de sorgo e concentrado para cordeiros. De maneira similar, Hubner et al. (2008) concluíram que o incremento do nível de FDN na dieta afetou o consumo de matéria seca, com reflexos diretamente proporcionais sobre os tempos despendidos em ingestão e ruminação e inversamente proporcionais sobre o tempo de ócio dos animais.

Segundo Dehority \& Tirabasso (2001), a frequência de alimentação pode afetar a concentração de microrganismos no rúmen e os parâmetros ruminais, o que pode afetar o consumo e o ganho de peso dos animais. Todavia, esses autores verificaram que, com dieta baseada em volumosos, a frequência de alimentação (uma, seis ou 24 vezes ao dia) não afetou os parâmetros estudados.

Os pesos e rendimentos de carcaça não foram influenciados $(\mathrm{P}>0,05)$ pela frequência de alimentação

Tabela 4 - Comportamento ingestivo de cordeiros em confinamento, no período de 24 horas, de acordo com a frequência de alimentação

\begin{tabular}{lcccccc}
\hline Variável & \multicolumn{3}{c}{ Frequência de alimentação } & Média geral & CV (\%) & Probabilidade \\
\cline { 2 - 4 } & 1 & 2 & 3 & & \\
\hline Ingerindo (minutos) & 250,00 & 246,70 & 291,70 & 262,80 & 17,75 \\
Ruminando (minutos) & 448,30 & 466,70 & 448,30 & 454,40 & 20,46 \\
Ócio (minutos) & 751,70 & 736,70 & 710,00 & 732,80 & 14,02 \\
Ingerindo (\%) & 17,24 & 17,01 & 20,11 & 18,12 & 17,75 \\
Ruminando (\%) & 30,92 & 32,18 & 30,92 & 31,34 & 0,7795 \\
Ócio (\%) & 51,84 & 50,80 & 48,97 & 50,54 & 20,46 & 0,9256 \\
\hline
\end{tabular}


(Tabela 5). Estes resultados já eram esperados, uma vez que não foi observada diferença significativa no peso corporal final (Tabela 3). O rendimento de carcaça quente e o rendimento verdadeiro foram maiores que os encontrados por Pereira et al. (2007) em cordeiros Santa Inês confinados e abatidos com 32,9 kg (respectivamente, 44,6 e 50,3\%,).

Segundo Osório \& Osório (2005), os principais fatores que influenciam o rendimento de carcaça são raça ou genótipo, idade, sexo e sistema de alimentação. Como a frequência de alimentação não afetou o desempenho, não foi observada diferença significativa na avaliação dos rendimentos de carcaça $(\mathrm{P}>0,05)$. A média para rendimento de carcaça quente $(48,0 \%)$ concorda com as médias para rendimentos de carcaça quente em ovinos (42 a 50\%) citadas por Silva Sobrinho (2001).

Os componentes não carcaça (Tabela 6) não foram influenciados pelo número de alimentações $(\mathrm{P}>0,05)$, apesar de os rendimentos dos intestinos cheios e do conteúdo do trato gastrintestinal terem apresentado diferença significativa $(\mathrm{P}<0,05)$. Possivelmente isso ocorreu devido ao maior tempo entre a última alimentação e o abate, apesar de o período de jejum e o tempo despendido para ingestão de alimento terem sido similares. Pazdiora (2008) observou em bovinos, que os animais passavam mais tempo alimentando-se logo após o oferta de alimentos, mas que o aumento na frequência do fornecimento não afetou o tempo total despendido com a alimentação. Chase et al. (1976) também observaram que a oferta de alimento induziu o animal a procurar e ingerir alimentos.

De maneira geral, os rendimentos dos componentes não carcaça, em ralação ao peso corporal final, concordam com os rendimentos apresentados por Furusho-Garcia et al. (2003) e Pereira et al. (2007) para cordeiros Santa Inês confinados, e por Ribeiro et al. (2004) para cordeiros mestiços de três grupos genéticos, Hampshire Down, Ile de France e Suffolk.

Entre as medidas tomadas nas carcaças, a frequência de alimentação influenciou $(\mathrm{P}<0,05)$ a largura da perna (Tabela 7). Carcaças de cordeiros alimentados duas vezes ao dia apresentaram maior média. Os resultados divergem dos relatados por Jardim et al. (2000), que avaliaram diferentes sistemas de terminação de cordeiros e observaram que, nos sistemas em que o desempenho e o peso ao abate foram similares, a biometria das carcaças também foi semelhante. De modo similar, Ferreira et al. (2009) também não encontraram diferenças nas medidas de carcaça de vacas e novilhos quando aumentaram a frequência

Tabela 5 - Características de carcaça de cordeiros em confinamento, de acordo com a frequência de alimentação

\begin{tabular}{|c|c|c|c|c|c|c|}
\hline \multirow[t]{2}{*}{ Variável } & \multicolumn{3}{|c|}{ Frequência de alimentação } & \multirow[t]{2}{*}{ Média geral } & \multirow[t]{2}{*}{ CV (\%) } & \multirow[t]{2}{*}{ Probabilidade } \\
\hline & 1 & 2 & 3 & & & \\
\hline Peso do corpo vazio (kg) & 32,98 & 33,16 & 34,19 & 33,45 & 10,50 & 0,8780 \\
\hline Rendimento de carcaça quente (\%) & 47,11 & 51,40 & 47,90 & 48,80 & 10,44 & 0,5539 \\
\hline Rendimento verdadeiro $(\%)^{1}$ & 53,86 & 60,93 & 54,97 & 57,17 & 12,98 & 0,3691 \\
\hline
\end{tabular}

${ }^{1}$ Rendimento de carcaça em relação ao peso do corpo vazio.

Tabela 6 - Rendimento (\%) dos componentes não-carcaça de cordeiros em confinamento, de acordo com a frequência de alimentação ${ }^{1}$

\begin{tabular}{|c|c|c|c|c|c|c|}
\hline \multirow[t]{2}{*}{ Variável } & \multicolumn{3}{|c|}{ Frequência de alimentação } & \multirow[t]{2}{*}{ Média geral } & \multirow[t]{2}{*}{ CV (\%) } & \multirow[t]{2}{*}{ Probabilidade } \\
\hline & 1 & 2 & 3 & & & \\
\hline Pele & 9,82 & 8,61 & 9,89 & 9,34 & 12,13 & 0,2236 \\
\hline Cabeça & 6,12 & 5,65 & 5,98 & 5,88 & 5,34 & 0,1535 \\
\hline Patas & 2,46 & 2,68 & 2,61 & 2,60 & 9,91 & 0,5099 \\
\hline RROA $^{2}$ cheios & 11,08 & 14,28 & 12,65 & 12,93 & 17,48 & 0,2009 \\
\hline $\mathrm{RROA}^{2}$ vazios & 2,67 & 3,38 & 2,98 & 3,07 & 14,08 & 0,1278 \\
\hline Intestinos cheios & $5,86 b$ & $8,96 a$ & $8,70 \mathrm{a}$ & 8,10 & 17,86 & 0,0381 \\
\hline Intestinos vazios & 3,54 & 3,88 & 4,47 & 3,99 & 15,88 & 0,1924 \\
\hline Conteúdo trato gastrintestinal & $10,73 c$ & $15,99 a$ & $13,89 b$ & 13,97 & 17,36 & 0,0463 \\
\hline Pulmão+traqueia & 1,45 & 1,75 & 1,25 & 1,51 & 22,57 & 0,1391 \\
\hline Gordura interna & 2,47 & 3,38 & 2,59 & 2,89 & 34,61 & 0,3932 \\
\hline Coração & 0,44 & 0,48 & 0,40 & 0,44 & 14,42 & 0,1899 \\
\hline Fígado & 1,70 & 1,96 & 1,59 & 1,77 & 13,65 & 0,1148 \\
\hline Baço & 0,17 & 0,16 & 0,15 & 0,16 & 22,23 & 0,8359 \\
\hline Rins & 0,28 & 0,31 & 0,28 & 0,29 & 11,11 & 0,1926 \\
\hline Testículos & 1,65 & 1,49 & 1,32 & 1,48 & 21,27 & 0,4124 \\
\hline
\end{tabular}

${ }^{1}$ Rendimento em relação ao peso corporal final.

2 RROA = rúmen + reticulo + omaso + abomaso.

a,b,c Médias na linha seguidas por letras diferentes diferem $(P<0,05)$ entre si. 
Tabela 7 - Medidas biométricas (cm) de carcaças de cordeiros em confinamento, de acordo com a frequência de alimentação

\begin{tabular}{|c|c|c|c|c|c|c|}
\hline \multirow[t]{2}{*}{ Variável } & \multicolumn{3}{|c|}{ Frequência de alimentação } & \multirow[t]{2}{*}{ Média geral } & \multirow[t]{2}{*}{ CV (\%) } & \multirow[t]{2}{*}{ Probabilidade } \\
\hline & 1 & 2 & 3 & & & \\
\hline Comprimento interno de carcaça & 65,17 & 68,90 & 65,00 & 66,67 & 5,43 & 0,2481 \\
\hline Profundidade do tórax & 27,33 & 27,80 & 26,25 & 27,17 & 6,40 & 0,4398 \\
\hline Comprimento da perna & 37,83 & 38,50 & 39,38 & 38,29 & 7,30 & 0,9469 \\
\hline Largura da perna & $7,50 \mathrm{c}$ & $10,30 \mathrm{a}$ & $9,00 \mathrm{~b}$ & 9,17 & 9,13 & 0,0043 \\
\hline Profundidade da perna & 12,83 & 16,40 & 14,38 & 14,83 & 19,34 & 0,2687 \\
\hline Comprimento da paleta & 20,83 & 20,30 & 21,13 & 20,71 & 4,60 & 0,4617 \\
\hline Perímetro da paleta & 14,50 & 15,30 & 14,75 & 14,92 & 9,88 & 0,7378 \\
\hline Espessura de gordura de cobertura & 4,00 & 4,40 & 4,50 & 4,33 & 19,15 & 0,7214 \\
\hline
\end{tabular}

a,b,c Médias na linha seguidas por letras diferentes diferem $(\mathrm{P}<0,05)$ entre si.

alimentar de duas até quatro vezes ao dia. Os autores atribuíram o resultado à semelhança no peso das carcaças e observaram correlação significativa entre o peso de carcaça e as medidas biométricas.

A média da espessura de gordura de cobertura foi 4,33 mm e não foi influenciada pela frequência de alimentação $(\mathrm{P}>0,05)$. De acordo com Silva Sobrinho (2001), as carcaças ovinas são classificadas como magras (gordura ausente), com gordura escassa (1 a $2 \mathrm{~mm}$ ), com gordura mediana (acima de 2 a $5 \mathrm{~mm}$ ), com gordura uniforme (acima de 5 a $10 \mathrm{~mm}$ ) e com gordura excessiva (acima de $10 \mathrm{~mm}$ ). Muller (1987) e Luchiari Filho (2000) comentaram que, se a gordura não for excessiva, contribui na porção comestível da carcaça, além de protegê-la da desidratação, do escurecimento da parte externa e do encurtamento celular, o que torna a carne mais dura. Para evitar esses problemas, é necessário um mínimo de 2 a 3 mm, de acordo com Luchiari Filho (2000).

Considerando os resultados obtidos neste estudo e o custo de mão-de-obra e logística, recomenda-se a utilização de apenas uma alimentação ao dia, corroborando com afirmação de Dehority \& Tirabasso (2001) de que não há vantagens práticas ou biológicas em alimentar ovinos confinados mais de uma ou duas vezes ao dia.

\section{Conclusões}

O aumento na frequência de alimentação de cordeiros em confinamento, de uma até três vezes ao dia, em dietas com $16 \%$ de PB e 70,3\% de NDT, não influencia o consumo de nutrientes, o ganho de peso diário, o comportamento ingestivo e o rendimento de carcaça, portanto, recomenda-se o fornecimento uma vez ao dia.

\section{Agradecimentos}

Os autores agradecem ao Conselho Nacional de Pesquisa e Desenvolvimento (CNPq) pelas bolsas de produtividade em pesquisa de Ribeiro e Mizubuti.

\section{Referências}

ARNOLD, A.M.; MEYER, H.H. Effects of gender, time of castration, genotype and feeding regimen on lamb growth and carcass fatness. Journal of Animal Science, v.66, p.2468-2475, 1988.

BESERRA, L.T.; CÂNDIDO, M.J.D.; MENESES, A.J.G. et al. Comportamento de caprinos confinados recebendo dietas à base de silagem de capim-elefante contendo bagaço de caju desidratado em dois sistemas de arraçoamento. In: REUNIÃO ANUAL DA SOCIEDADE BRASILEIRA DE ZOOTECNIA, 44., 2007, Jaboticabal. Anais... Jaboticabal: Sociedade Brasileira de Zootecnia, 2007. (CD-ROM).

CAMPOS, J. Tabelas para cálculo de rações. 2.ed. Viçosa, MG: Universidade Federal de Viçosa, 1995. 64p.

CARVALHO, G.G.P.; PIRES, A.J.V.; SILVA, R.R. et al. Aspectos metodológicos do comportamento ingestivo de ovinos alimentados com capim-elefante amonizado e subprodutos agroindustriais. Revista Brasileira de Zootecnia, v.36, n.4, p.1105-1112, 2007a.

CARVALHO, S.; BROCHIER, M.A.; PIVATO, J. et al. Ganho de peso, características da carcaça e componentes não-carcaça de cordeiros da raça Texel terminados em diferentes sistemas alimentares. Ciência Rural, v.37, n.3, p.821-827, 2007b.

CAVALCANTI, M.C.A.; BATISTA, A.M.V.; GUIM, A. et al. Consumo e comportamento ingestivo de caprinos e ovinos alimentados com palma gigante (Opuntia ficus-indica Mill) e palma orelha-de-elefante (Opuntia sp.). Acta Scientiarum. Animal Sciences, v.30, n.2, p.173-179, 2008.

CHASE, L.J.; WANGSNESS, P.J.; BAUMGARDT, B.R. Feed behavior of steers fed a complete mixed ration. Journal of Dairy Science, v.59, n.11, p.1923-1928, 1976.

DEHORITY, B.A.; TIRABASSO, P.A. Effect of feeding frequency on bacterial and fungal concentrations, $\mathrm{pH}$, and other parameters in the rumen. Journal of Animal Science, v.79, p.2908-2912, 2001.

FERREIRA, J.J. Desempenho e comportamento ingestivo de novilhos e vacas sob frequências de alimentação em confinamento. 2006. 97f. Dissertação (Mestrado em Zootecnia) - Universidade Federal de Santa Maria, Santa Maria.

FERREIRA, J.J.; MENEZES, L.F.G.; RESTLE, J. et al. Características de carcaça de vacas de descarte e novilhos mestiços Charolês x Nelore em confinamento sob diferentes frequências de alimentação. Revista Brasileira de Zootecnia, v.38, n.10, p.1974-1982, 2009.

FURUSHO-GARCIA, I.F.; PEREZ, J.R.O.; TEIXEIRA, J.C. Componentes de carcaça e composição de alguns cortes de cordeiros Texel x Bergamácia, Texel x Santa Inês e Santa Inês puros, terminados em confinamento, com casca de café como parte da dieta. Revista Brasileira de Zootecnia, v.32, n.6, p.1999-2006, 2003 (supl. 2). 
GIMENES, A.L.G.; MIZUBUTI, I.Y.; MOREIRA, F.B. et al. Composição química e estabilidade aeróbia em silagem de milho preparada com inoculante bacteriano e/ou enzimático. Acta Scientiarum.Animal Science, v.28, n.2, p.153-158, 2006.

HUBNER, C.H.; PIRES, C.C.; GALVANI, D.B. et al. Comportamento ingestivo de ovelhas em lactação alimentadas com dietas contendo diferentes níveis de fibra em detergente neutro. Ciência Rural, v.38, n.4, p.1078-1084, 2008.

JARDIM, R.D.; OSÓRIO, J.C.S.; OLIVEIRA, N.M. et al. Características produtivas e comerciais de cordeiros da raça Corriedale criados em distintos sistemas nutricionais. Revista Brasileira de Agrociência, v.6, n.3, p.239-242, 2000 .

KOZLOSKI, G.V.; TREVISAN, L.M.; BONNECARRÈRE, L.M. et al. Níveis de fibra em detergente neutro na dieta de cordeiros: consumo, digestibilidade e fermentação ruminal. Arquivos Brasileiros de Medicina Veterinária e Zootecnia, v.58, n.5, p.893-900, 2006.

KOZLOSKI, G.V.; CADORIN JÚNIOR, R.L.; HARTER, C.J. et al. Effect of suplemental nitrogen source and feeding frequency on nutrient supply to lambs fed a kikuyu grass (Pennisetum clandestinum) hay-based diet. Small Ruminant Research, v.81, p.112-118, 2009.

LUCHIARI FILHO, A. Pecuária da carne bovina. São Paulo: A. Luchiari Filho, 2000. 134p.

MACEDO, C.A.B.; MIZUBUTI, I.Y.; MOREIRA, F.B. et al. Comportamento ingestivo de ovinos recebendo dietas com diferentes níveis de bagaço de laranja em substituição à silagem de sorgo na ração. Revista Brasileira de Zootecnia, v.36, n.6, p.1910-1916, 2007.

MULLER, L. Normas para avaliação de carcaças e concurso de carcaças de novilhos. 2.ed. Santa Maria: Universidade Federal de Santa Maria, 1987. 31p.

NATIONAL RESEARCH COUNCIL - NRC. Nutrient requirements of sheep. Washington: National Academy Press, 1985. 99p.

NATIONAL RESEARCH COUNCIL - NRC. Nutrient requirement of small ruminants: Sheep, goats, cervids and new camelids. Washington: National Academy Press, 2007. $384 \mathrm{p}$.

OSÓRIO, J.C.S. Estudio de la calidad de canales comercializadas en el tipo ternasco según la procedencia: Bases para la mejora de dicha calidad en Brasil. 1992. 335f. Tese (Doutorado em Veterinária) - Universidad de Zaragoza, Zaragoza.
OSÓRIO, J.C.S.; OSÓRIO, M.T.M. Produção de carne ovina: Técnicas de avaliação "in vivo” e na carcaça. 2.ed. Pelotas: Ed. Universitária, 2005. 82p.

PAZDIORA, R.D. Frequências do fornecimento do volumoso e concentrado no desempenho e comportamento ingestivo de vacas e novilhas em confinamento. 2008. $80 \mathrm{f}$ Dissertação (Mestrado em Zootecnia) - Universidade Federal de Santa Maria, Santa Maria.

PEREIRA, M.S.; RIBEIRO, E.L.A.; MIZUBUTI, I.Y. et al. Carcaça e não-componentes da carcaça de cordeiros recebendo polpa cítrica úmida prensada em substituição à silagem de milho. Acta Scientiarum.Animal Sciences, v.29, n.1, p.57-62, 2007.

PEREIRA, M.S.; RIBEIRO, E.L.A.; MIZUBUTI, I.Y. et al. Consumo de nutrientes e desempenho de cordeiros em confinamento alimentados com dietas com polpa cítrica úmida prensada em substituição à silagem de milho. Revista Brasileira de Zootecnia, v.37, n.1, p.134-139, 2008.

RAKES, A.H.; LISTER, E.E.; REID, J.T. Some effects of feeding frequency on the utilization of isocaloric diets by young and adult sheep. Journal of Nutrition, v.75, p.86-92, 1961.

RIBEIRO, E.L.A.; ROCHA, M.A.; MIZUBUTI, I.Y. et al. Silagem de girassol (Helianthus annus L.), milho (Zea mays L.) e sorgo (Sorghum bicolor (L.) Moench) para ovelhas em confinamento. Ciência Rural, v.32, n.2, p.299-302, 2002.

RIBEIRO, E.L.A.; ROCHA, M.A.; MIZUBUTI, I.Y. et al. Desempenho de cordeiros desmamados aos 67 dias alimentados com silagem de milho e feno de aveia. Semina.Ciências Agrárias, v.24, n.1, p.85-92, 2003.

RIBEIRO, E.L.A.; SILVA, L.D.F.; MIZUBUTI, I.Y. et al. Componentes do peso vivo em cordeiros inteiros ou submetidos a diferentes métodos de castração. Revista Brasileira de Ciências Veterinárias, v.11, n.1/2, p.80-83, 2004.

SILVA, D.J.; QUEIROZ, A.C. Análise de alimentos (métodos químicos e biológicos). 3.ed. Viçosa, MG: Universidade Federal de viçosa, 2002. 235p.

SILVA SOBRINHO, A.G. Criação de ovinos. 2.ed. Jaboticabal: FUNEP, 2001. 302p.

STATISTICAL ANALYSIS SYSTEM - SAS. SAS/STAT User2 sgGuide. Cary: SAS Institute, 1994. 1686p.

VALADARES FILHO, S.C.; MAGALHÃES, K.A.; ROCHA JUNIOR, V.R. et al. Tabelas brasileiras de composição de alimentos para bovinos. 2.ed. Viçosa, MG: Universidade Federal de Viçosa, 2006. 329p.

VAN SOEST, P.J. Nutritional ecology of the ruminant. 2.ed. Ithaca: Cornell University Press, 1994. 476p. 